\title{
Questão energética na Amazônia: disputa em torno de um novo padrão de desenvolvimento econômico e social
}

\author{
The energy question in Amazonia: a debate on a new standard of economic \\ and social development
}

Maria Célia Nunes Coelho - Mestre em Geografia pela PPGG/UFRJ. PhD em Geografia pela Universidade de Syracuse, EUA. Pesquisadora do CNPq. E-mail: mcncoelho@gmail.com

Elis Miranda - Mestre pelo NAEA e Doutorado pelo IPPUR/UFRJ. Professora de Geografia da UFF/Campus. Coordenadora de projetos de Pesquisa junto ao CNPQ e FAPERJ. E-mail: elismiranda10@gmail.com

Luis Jardim Wanderley - Mestre em Geografia pela PPGG/UFRJ. Doutorando do PPGG/UFRJ. Suas principais áreas de interesse são: Conflitos sociais, Mineração e Geografia Agrária. E-mail: lulajardim@hotmail.com

Tomás Coelho Garcia. - Graduado em Ciências Sociais pela UFRJ e doutorando em Sociologia pelo Instituto de Estudos Sociais e Políticos (IESP-UERJ). Integra o Laboratório da Conjuntura Social: Tecnologia e Território (LASTRO).E-mail: tomas_lastro@yahoo.com.br

\section{Resumo}

As usinas hidrelétricas na Amazônia ocidental brasileira (Santo Antônio, Jirau e Belo Monte, em processos de construção ou de decisões) são projetos infraestruturais potencialmente estruturantes. Elas não são objetos técnicos recentes nem tampouco isolados. Suas execuções suscitam polêmicas e diferentes críticas ou defesas. O objetivo principal do artigo é articular os planos de construção de usinas e a formação de redes sulamericanas de transmissão de energia elétrica e de gasodutos com os processos de produção, de comercialização internacional de mercadorias e de dinamização de corredores de exportação de commodities de forma coerente ao modelo de desenvolvimento vigente. Assim, o trabalho proposto consistiu em examinar os contextos atuais de criação destas hidrelétricas, suas relações com os planos de integração da América do Sul e seus impactos locais/regionais. As perspectivas adotadas foram: A) análise histórica evolutiva; e B) comparação de dados relativos ao consumo e ao desenho das redes de energia integradas (em construção) apresentadas por países da América do Sul limítrofes do Brasil.

\section{Palavras-chave}

Usinas Hidrelétricas de Jirau. Santo Antônio e Belo Monte. Padrão de desenvolvimento. Rede. Energia. Amazônia América do sul.

\begin{abstract}
The hydroelectric power stations located in the Western Brazilian Amazon region (Santo Antônio, Jirau and Belo Monte - still under construction or undergoing decision processes) are potentially structuring infrastructural projects. These power stations are neither recent nor isolated technical projects. The execution of these projects raises controversy and a varied array of criticism or defense. This paper articulates power station construction plans and the formation of South American energy transmission networks with the dynamic commodity export corridors, coherently linking them with the current development model. The article also examines the current framework in which the hydroelectric power stations are located, their relations with the integration plans for South America and their local and regional impacts. The standpoints used in this work are: a) historical evolutionary analysis; and b) data comparison regarding consumption and the integrated energy networks design (in construction) presented by South American countries bordering Brazil.
\end{abstract}

\section{Keywords}

Hidreletics of Jirau. Santo Antônio e Belo Monte. Networks. Energy. Amazônia. América do sul. 


\section{INTRODUÇÃO}

Além de impactos físico-sociais locais historicamente traumáticos, o que está em jogo, contemporaneamente, nas discussões a cerca das novas hidrelétricas na Amazônia ocidental brasileira? Sem dúvida, o espectro de um passado historicamente repudiado, é responsável por um clima de aparente deja vu: ações de denúncias, sentimentos de "vitimizações", ainda vivos entre partes das populações locais, de um lado, atitudes de insensibilidades, de arrogâncias e de não adoções de enfoques em redes comerciais e sociais amplas. Mas o que há de diferente do período da construção da Usina de Tucuruí no Pará e Balbina no estado do Amazonas? Além de possuir potencial hidrelétrico elevado, o Brasil é vizinho, na América do Sul, de países ricos em reservas de gás, petróleo e energia hidroelétrica. Como então tirar partido de tudo isto? Ou ainda, qual a relação destes projetos energéticos com os programas de integração dos países da América do Sul?

A Usina Hidrelétrica de Belo Monte, na Volta Grande do Rio Xingu no município de Altamira - PA, a ser concluída a partir de 2015, com capacidade para a geração de 11.233 MW de energia, a terceira maior do mundo em geração, e as usinas em construção, de Santo Antônio e Jirau, no Rio Madeira, rio nascido na Cordilheira dos Andes, na Bolívia, são tidas como as "estrelas" do Programa de Aceleração Crescimento - PAC do governo federal. Segundo a Revista Exame, de abril de 2010 (p. 38), dentre as maiores usinas hidrelétricas, estão Três Gargantas (China) com potência instalada em megawatts de 22 500; Itaipu (Brasil/Paraguai) com 14 000; Guri (Venezuela) 10 000; Grand Coulee (EUA) 6.000; e as Usinas do Madeira (Santo Antônio e Jirau, juntas) 6.450, sendo Santo Antônio sozinha, com 3150 megawats.

As usinas hidrelétricas em construção na Amazônia ocidental brasileira (Santo Antônio, Jirau e Belo Monte) e outras planejadas (no Rio Tapajós, por exemplo) são polêmicas e suscitam diferentes disputas, polêmicas, críticas ou defesas. De um lado, as obras são criticadas por movimentos sociais, lideranças indígenas e ribeirinhas, por não considerarem de forma satisfatória os impactos físico-socioambientais. Por outro lado, para os defensores, estas usinas, além de serem indispensáveis à segurança energética e ao atendimento da crescente demanda nacional de energia elétrica, contribuirão para supremacia da rede de energia renovável, de baixo custo, isenta de emissões poluentes e gasosas.

As redes energéticas, viárias e infoviárias, bem como a rede de fluxos de compra e venda etc., são criadas pela necessidade de dotar o território de maior fluidez, no médio e longo prazos. Neste contexto, acham-se incluídos projetos de formação de "fronteiras econômicas" ou de "fronteiras de commodities"1 sobrepostas às fronteiras políticas. As diferentes fronteiras envolvem quase sempre a criação de leis, regras e medidas, dentre as quais a formação de redes técnicas, de negócios e de movimentos sociais. As medidas de ampliação de infraestruturas físicas (estradas, pontes, etc.), financeiras e tributárias seguem um dado modelo econômico, visando forjar o presente e o futuro, já historicamente trabalhados incorporando ao planejamento regiões ou países vizinhos.

Em suma, a propósito da discussão suscitada pelas hidrelétricas aqui consideradas, destacamos, repetindo o já aqui exposto, que as questões que nortearam a elaboração deste trabalho são: a) o que está por detrás destes conflitos, confrontos e negociações? b) Quais as relações estabelecidas entre as redes energéticas do Brasil e o desenvolvimento dos planos de integração e controle das fronteiras políticas, isto é, entre países da América do Sul? Será, certamente, o processo de "commoditização" (outro neologismo derivado do termo inglês, commodity) e a formação de redes (hidrelétrica ou de termoelétrica movidas a gás) de transmissão energética, regional, nacional ou mesmo internacional utilizadas para fortalecer os processos de industrialização, de corredores de exportação de commodities in natura ou semitransformadas e de forma concernente ao modelo privilegiado? Ou quais são ou seriam as vantagens de formação de redes de energia no processo desenvolvimento regionais, nacionais ou internacionais?

Dessa forma, o presente artigo acha-se organizado em quatro partes. A primeira diz respeito à ocupação da Amazônia, tratando especificamente da Hidrelétrica de Tucuruí, com início da obra em 1974 e inaugurada em 1984; das hidrelétricas de Belo Monte, de Santo Antônio e de Jirau, em processo de construção ou de licenciamento. A segunda parte trata das perspectivas de mudanças no padrão de consumo de energia interligadas por rede no Brasil e nos demais países da América do Sul. A terceira apresenta as considerações sobre as críticas e as incertezas na continuidade da aplicação dos ditames do modelo econômico até agora seguido. E, por fim, na quarta parte, versa-se sobre as conclusões, que são por natureza incompleta ou temporal.

Por fronteiras econômicas estamos entendendo a incorporação de novas áreas à economia, enquanto por fronteiras políticas correspondem à faixa de fronteira entre países. As fronteiras econômicas podem se sobreporem as fronteiras políticas. Por fronteira de commodity estamos entendendo a corrida para a produção de matérias-primas demandadas pelos mercados internacionais, ou seja, correspondem à integração de novas áreas à economia motivadas por demandas crescentes e pelos preços em altas. 


\section{PROCESSO DE OCUPAÇÃO DA AMAZÔNIA BRASILEIRA}

Com as crises do petróleo de 1972 e 1979, o Brasil, estimulado pelo governo japonês, viu-se incentivado a construir a usina hidrelétrica de Tucurui, visando gerar energia subsidiada, para atrair a indústria eletrointensiva do alumínio para a Amazônia brasileira. Dessa forma, segundo o II Plano Nacional (PND) (1974 1779), não só a hidrelétrica de Tucuri foi planejada, mas foi estimulada a criação da Mineração Rio do Norte (MRN) em Oriximiná, no Pará, para produção da matéria-prima mineral - a bauxita. Além destes, outros projetos foram implantados seguindo a lógica de planejamento do desenvolvimento regional: a abertura da Transamazônica; a implantações dos projetos associados ao POLOAMAZÔNIA; o Projeto Grande Carajás (PGC) (Projetos das décadas de 1970 e 1980); os avanços da pecuária, da mineração e agora da soja, do cobre e níquel e da implantação de mínero-siderurgias.

A energia de Tucuruí abastecia as fábricas da Alumar, a cidade de Belém, as fábricas da multinacional Alcoa, em São Luís, no Maranhão, mas também a Alunorte e a Albras, esta última uma união via joint-venture entre a Companhia Vale do Rio Doce (CVRD) e firmas japonesas, instalada em Barcarena, no Pará. Ao mesmo tempo, foi estimulada a criação do corredor Carajás, a partir da Estrada de Ferro Carajás (EFC), que passou a ligar as minas de ferro e manganês em Carajás - $\mathrm{PA}^{2}$ ao porto de Madeira-Itaqui em São Luís do Maranhão. Ao longo da EFC, cresceram os centros produtores de ferro-gusa no Pará e no Maranhão. Assim, a energia de Tucurui contribuiu para viabilizar mais este corredor. Um outro corredor, formado pelo Rio Tocantins, beneficiado pela energia de Tucuruí, teve seu estimulo postergado pelos adiamentos, por mais de 30 anos, das obras de conclusão das eclusas de Tucuruí e está sendo atualmente contemplado pelas obras do PAC.

Em 1996, Eliézer Bastista da Silva, ex-presidente da CVRD, hoje apenas Vale, já tinha elaborado uma proposta de desenvolvimento segundos eixos de integração (grandes rotas - naturais ou artificiais, modais ou intermodais: rios, estradas, ferrovias, hidrovias, dutos, etc.) visando à circulação maior das matériasprimas ou das commodities minerais e agrícolas, seguida pelo Brasil e pelos demais países da América do Sul.

Mais tarde outros minérios foram incorporados: ouro e cobre, por exemplo.
1.1 O Povoamento da Amazônia Oriental durante e depois da construção de uma Rede de Energia Hidrelétrica. $O$ caso de Tucuruí e da rede gerada

A hidrelétrica de Tucuruí, na cidade de Tucuruí, no vale do Rio Tocantins, estado do Pará, foi construída (de 1974 a 1984) pelas empreiteiras Camargo Correia e Queiroz Galvão. A UHE Tucuruí afetou dramaticamente as populações indígenas e pequenos agricultores ribeirinhos. Os índios Parakana, habitantes das margens do rio Tocantins, foram removidos para outras áreas distante do rio. As populações de pequenos agricultores ribeirinhos foram transferidas para áreas distantes do rio e dos mercados. Passada o pico da construção da usina (1982) grande parte da mão de obra que trabalhava na obra foi dispensada e passou a ocupar as periferias urbanas de Marabá no Pará, Imperatriz e Açailândia no Maranhão, principalmente. Muitos também se dirigiram para o garimpo de Serra Pelada, sendo, muitos destes, posteriormente, recrutados pelo Movimento de Trabalhadores Sem Terra (MST) nas periferias das cidades como Parauapebas, Curionópolis, Marabá no estado do Pará ou Imperatriz e Açailândia, no estado do Maranhão.

Os núcleos de povoamento ao longo da Transamazônica já se transformaram em cidades, sede de municípios. Muitas cidades de médias ou pequenas, porém, numerosas se especializam cada vez mais em serviços urbanos, sendo utilizadas como sedes de sindicatos, de movimentos sociais, ou como centros administrativos, comerciais e de serviços. A rede de cidades é cada vez mais liderada por centros industriais regionais e cidades regionais de função portuária, como: Altamira (no Xingu), Santarém (no Tapajós) e Marabá (no Tocantins) e por cidades sedes de grandes empresas mineradoras: Parauapebas - Canaã dos Carajás, Oriximiná e Juruti. Identifica-se, assim, a evolução de extensa rede de cidades, estimuladas por planos dinamizadores da economia regional que tenderão a se expandir em direção à Amazônia ocidental.

1.2 Fase contemporânea do processo de ocupação da Amazônia Ocidental: o caso da Hidrelétrica de Belo Monte e a rede a ser construída

Inicialmente batizada como Kararaô, a usina rebatizada de Belo Monte nasceu dentro de um complexo de seis hidrelétricas. O projeto da Hidrelétrica de Belo Monte foi planejada há mais de 35 anos (desde a criação da Eletronorte, 
subsidiária da Eletrobrás, em 1975), do período dos governos militares ditatoriais (1964-1985) até os governos do Presidente Luiz Inácio Lula da Silva (dois mandatos - de 2003-2010) este projeto foi várias vezes alterado. Para chegar ao desenho atual, o projeto da usina hidrelétrica de Belo Monte passou por diferentes modelagens, com mudanças na sua denominação e redimensionamento, visando com isto, reduzir os impactos físico-socioambientais e atender as reivindicações locais, ainda que precariamente. Em face dos protestos indígenas, ela foi rebatizada como Belo Monte.

Segundo Maurício Tolmasquim 3 "o projeto atual difere daquele dos anos 1980. Não afeta diretamente terras indígenas e reduz a área alagada em $60 \%$, para $516 \mathrm{~km}^{2}$ ". Houve ainda a desistência de construção das outras hidrelétricas que formariam o complexo.

Assim, na primeira década de 2000, o projeto ressurgiu cercado de polêmicas e dúvidas quanto à sua viabilidade econômica, sua real pertinência, seus impactos e seus benefícios sociais. Enfim, este projeto acirra divisões entre economistas, mesmo desenvolvimentistas ${ }^{4}$, entre governos, federais e estaduais, e demais atores sociais.

Embora no caso da usina de Belo Monte, o presidente da Empresa de Pesquisa Energética (EPE), Maurício Tolmasquim, afirmasse que os indígenas não seriam diretamente afetados, temos que considerar que isto é apenas uma das muitas interpretações possíveis e que a experiência de remoção de populações indígenas e ribeirinhas durante a implantação da Usina Hidrelétrica de Tucuruí ainda é viva na memória coletiva.

Não obstante a persistência do mito de "vazio" demográfico, o vale do rio Xingu é atualmente relativamente bem povoado. O rio Xingu, afluente da margem direita (meridional) do rio Amazonas, nasce no Planalto Central no Mato Grosso e banha, em seu alto curso, o Parque Indígena do Xingu, moradia de 14 etnias e cerca de 5 mil índios (Revista Carta Capital - 28 de abril de 2010, p.23).

Um sobrevôo sobre o Parque Indígena do Xingu mostra que o desmatamento sistemático avançou sobre a floresta até suas bordas. São campos de soja e pastos para a criação de gado a comprometer nascentes e a arrancar da mata sua capacidade de manter a vida. A floresta resiste ainda intacta apenas nos 26 mil quilômetros quadrados do parque.

Folha de São Paulo, Dinheiro, p.B4, de 18/04/2010.

4 Quer da corrente do ministro do Planejamento do governo Lula da Silva, Guido Mantega ou de Dilma Rousseff, eleita presidente do Brasil no último pleito, quer da Eletrobrás ou do Banco Nacional de Desenvolvimento Econômico Social - BNDES.
A natureza local há muito não é mais intocada, desde que neste vale se instalaram os primeiros indígenas e na fase muito anterior ao período colombiano. Os poucos estudos sistemáticos realizados no campo da arqueologia revelam vestígios de populações muito antigas e que, certamente, contam uma história que pode ter começado há séculos.

Se não fosse por isto, estas paisagens, em tempos relativamente recentes, já teriam sido alteradas pelas extensas fazendas de gado que lá se instalaram desde as décadas de 1970 e 1980. Há que se lembrar que a região do Xingu, a retaguarda da então fronteira amazônica (sudeste e leste paraense) separa a região de Carajás, no sudeste do Pará; da região do Tapajós, área da atual expansão da fronteira econômica amazônica no Pará; área cortada pela BR-163 - a rodovia Cuiabá-Santarém.

O ambiente já milenarmente modificado corre o risco de perder ainda mais socio/biodiversidade. Os danos sobre o recurso água parecem claros ao constatar que algumas tribos indígenas contarão com problemas de acesso a esse recurso. O maior dano local associado às hidrelétricas está relacionado ao longo período de estiagem quando o leito dos reservatórios praticamente secarem, trazendo prejuízo como perda de biodiversidade, além de colocar as populações locais mais sujeitas a epidemias ${ }^{5}$.

A poluição ou escassez de água e demais problemáticas a elas associadas na hidrovia Paraguaí - Paraná, nas represas do Rio Madeira ou no Rio Xingu e nos gasodutos existentes e planejados (que interceptam ou interceptarão cursos d'água) podem estar vinculadas a impactos sociais e físicos ambientais e às políticas infraestuturais destinadas a promover as integrações entre países e regiões, com reforço das indústrias mineradoras ou das agroindústrias. A integração, sem promoção das desigualdades sociais e espaciais, dependerá, porém, de redefinição do modelo econômico com justiça para todos os povos ou não.

\subsection{O caso das empresas Jirau e Santo Antônio no estado de Rondônia}

Segundo a Revista Exame "o rio Madeira deverá ser o sexto polo hidrelétrico do mundo." A sete quilômetros a sudoeste de Porto Velho, capital do estado de Rondônia, o rio Madeira dá uma volta similar a do Rio Xingu. Nesta

\footnotetext{
5 Entrevista do Dr. Prof. Carlos B. Wainer, Globo News, 1 de maio de 2010.

6 Edição 966, no. 7 de 21/04/2010.
} 
zona de contato entre o cristalino e a bacia sedimentar há, portanto, rochas de granito, terreno propício à construção de hidrelétricas. Nas proximidades desta volta está sendo construída a hidrelétrica de Santo Antônio, uma empreitada de 13,5 bilhões de reais, a ser concluída em dezembro de 2011. Sua construção está a cargo da construtora Odebrecht, em parceria com a Andrade Gutierrez. Segundo Marcelo Odebrecht ${ }^{7}$ “'O sucesso de Santo Antônio é indispensável para consolidar nova fronteira hidrelétrica do país."

O consórcio vencedor em 2007 foi o Santo Antônio Energia - formado pelas estatais Furnas e Cemig, pelo FI FGTS, administrado pela Caixa Econômica Federal, pelo Banco Banif e pelos grupos Odebrecht e Andrade Gutierrez.

A Usina Hidrelétrica de Jirau é outra hidrelétrica em construção, também no rio Madeira. A construção está sendo feita pelo consórcio "ESBR - Energia Sustentável do Brasil", formado pelas empresas: Suez Energy (50.1\%), Eletrosul (20\%), Chefs (20\%) e Camargo Corrêa (9,9\%).

A usina, juntamente com a de Santo Antônio, são consideradas fundamentais para o suprimento de energia elétrica no Brasil a partir de meados de 2013 e estão sendo consideradas as obras mais importantes do Programa de Aceleração do Crescimento do Governo do Presidente Lula, elaborada pela candidata eleita presidente da república, Dilma Roussef.

Argumenta-se que a energia de Santo Antônio e Jirau resultarão em reservatórios menos impactantes que o de Balbina-AM, construída anos $1980^{8}$. Segundo governistas, ainda que a região Centro-Sul do país venha ser a maior consumidora destas energias geradas por Belo Monte, Santo Antônio e Jirau, a Amazônia ocidental também será beneficiada. Não mencionam, entretanto, as áreas fronteiriças com os países vizinhos, Bolívia e Peru.

\section{$1.4 \mathrm{O}$ caso das empresas interessadas em Belo Monte e demais hidrelétricas}

A época é de incertezas quanto ao futuro das economias mundiais. O leilão de 20 de abril de 2010 foi marcado por dúvidas e inseguranças. Embora conturbado, a desordem gerada por ocasião do leilão estivesse como justificativa

Revista Exame, Edição 966, no. 7 de 21/04/2010, p. 34

8 Considerada o maior desastre ambiental causado por uma hidrelétrica no Brasil e geradora de menos energia do que Santo Antônio. O reservatório de Balbina ocupa cerca de 2360 km, Santo Antônio de $271 \mathrm{~km}$ ou $110 \mathrm{~km}$ nas cheias e Jirau 4 km² de barragem. a tarifa barata imposta pelo governo federal. Este fato sem dúvida afugentou investidores privados. Dessa forma, o referido leilão foi marcado por verdadeira "guerra jurídica" que ganhou adesões e posições contrárias a sua aprovação dos Ministérios Públicos, federal e estaduais, que assumiram posições não defendidas pelo Governo Federal.

Analistas denunciaram os valores que foram subestimados pelo governo. Estimava-se que a obra custaria 28,5 bilhões, um valor bem acima da previsão oficial de R \$ 19 bilhões. Pequena lucratividade, riscos financeiros da obra, do projeto e de operações foram apontados como problemas que tornariam a obra pouco viável ou até mesmo inviável. Porém, os argumentos contra ou favoráveis à construção da hidrelétrica de Belo Monte vão além da problemática jurídica financeira.

As empresas envolvidas na construção da Hidrelétrica de Belo Monte são de três naturezas: a) as gestoras: Agência Nacional de Energia Elétrica (ANEEL), Eletrobras - Chesf; b) as construtoras; e c) as consumidoras. Além delas, deverão participar os fundos de pensão. As gestoras são a Eletrobras, suas subsidiárias e a Chesf. As construtoras de participação prevista eram grandes empresas com know-how de construtoras no país. E as empresas privadas de grande porte como a CVRD (Vale), a Alcoa, CSN, Votorantim e produtoras de commodities.

O consórcio Belo Monte Energia era composto pelo grupo Eletrobras e suas subsidiárias, duas estatais, Furnas e Eletrosul, a construtora Andrade Gutierrez, a CVRD (Vale), a Neoenergia e a Companhia Brasileira de Alumínio, divisão do grupo Votorantim e acabou perdendo o leilão realizado no dia 20 de abril.

O Consórcio Norte Energia foi o vencedor do leilão. A estatal Eletrobras Chesf (controlada pela Eletrobrás) foi apontada como líder do grupo vencedor. O Consócio vencedor é formado pela Queiroz Galvão Engenharia, Cetenco, Mendes Junior, Contern, Gaia, etc. Mas o consórcio está ainda em formação. O Grupo OAS, quinto maior do país na área de construção civil, deverá integrar este consórcio, que deverá também reunir as empresas participantes do consórcio anterior. Assim, a OAS surgiu ao lado da Queiroz Galvão e Bertin ${ }^{9}$ que disputaria Belo Monte com o grupo liderado pela Andrade Gutierrez ${ }^{10}$.

Além das gestoras e das construtoras, o grupo está ainda à procura de empresas que entrarão no projeto como investidores para garantir uma parcela da energia em suas fábricas. Os possíveis sócios serão a CVRD (Vale), que participou do consórcio perdedor, a Brakem (Petroquimíca), Gerdau, CSN, de interesse não

9 Tradicional companhia do setor frigorífico.

10 E que, todavia, não compareceu no dia 20 de abril como participante da disputa. 
confirmado e Alcoa. Dentre estas, a CVRD (Vale) e a Alcoa possuem mineradoras e siderurgias e projetos de transformação da bauxita em alumina e alumínio, instalados na região amazônica.

Os articuladores do projeto visam incentivar a Alcoa a implantar uma fábrica eletrointensiva de alumínio que ela afirma ser planejada para o Pará-Brasil, não obstante seus interesses atuais fora da América do Sul. A CVRD (Vale), além da expansão da Alunorte parecia, até maio de 2010, interessar-se por ampliar a produção de alumínio em Barcarena, a partir da expansão da mina de Paragominas, já que a extração de bauxita de Oriximiná está, na sua origem, comprometida com suas acionistas e com a Alunorte - Albras em Barcarena. No caso a CVRD (Vale) pode estar também interessada pela produção ampliada de aços planos, tal como da Gerdau e da Companhia Siderúrgica Nacional (CSN). O grupo Votoratim interessado no fornecimento de cimento para a construção de Belo Monte e na diversificação do grupo.

\section{PERSPECTIVAS DO DESENVOLVIMENTO (OU “MODERNIZAÇÃO” EXPANSIONISTA A QUALQUER PREÇO) PARA O BRASIL OU PARA A AMÉRICA DO SUL}

Os países da América do Sul não desistiram de lutar contra o subdesenvolvimento nem de insistir num futuro comum. A abundância de reservas de gás ou as riquezas hidrológicas leva-nos a repensar as relações econômicas e comerciais entre esses países. Falta organizar e fazer funcionar os Estados em torno de formação de redes políticas, redes técnicas, industriais e comerciais e redefinir as "fronteiras" nacionais e internacionais, atentando aos seus dinamismos.

Ao avaliarmos os meios geográficos, correspondentes aos limites entre Brasil e países vizinhos, concluímos pelas condições ou possibilidades de construções de novos espaços, verdadeiras fronteiras, para o desenvolvimento integrado planejado: inter-naçôes, fundamentados em propostas, a serem discutidas e traçadas de acordo com modelos econômicos menos dependentes do capitalismo global. Problemas e soluções futuras surgirão e deverão ser debatidas.
2.1 Tendência comum à mudança na estrutura de consumo de energia. Perspectiva de maior crescimento industrial?

A energia é e sempre foi vista como fator necessário ao desenvolvimento. Tanto teórico quanto politicamente, a relação entre os dois termos é construída por intermédio da industrialização: Energia à Industrialização ao Desenvolvimento. Se a relação "Industrialização ao Desenvolvimento" foi bastante problematizada pela teoria econômica, o mesmo não se pode falar de relação Energia à Industrialização. Isto porque esta relação raramente é pensada de forma tão direta - ou seja, relação com implicações lógicas. Em diversos discursos em que a energia é apresentada como um "entrave" ou "gargalo" do crescimento, é possível pensar energia como um elemento necessário, mas não suficiente para a industrialização e é esta relação que gostaríamos de ressaltar neste ponto.

Segundo dados da Empresa de Pesquisa Energética (EPE), ligada ao Ministério de Minas e Energia (MME), a última década (de 1999 a 2009) foi de amplo crescimento do consumo de energia no Brasil, em média 3,3\% ao ano, passando de 282 mil GWh para 388 mil GWh. O consumo de energia elétrica do setor residencial no Brasil apresentou valores inferiores ao consumo industrial para o Brasil como um todo, porém, as taxas de crescimento deste setor nos períodos de 1995 a 1997, dos anos de 2004 a 2006, e no ano de 2008 foram superiores às taxas de crescimento correspondentes ao setor industrial. As taxas de crescimento do setor residencial foram de uma média de $2,6 \%$ ao ano, enquanto o setor industrial aumentou em 3,3\% a.a. o consumo. ${ }^{11}$ Todavia, as taxas de crescimento superior do setor residencial nos períodos citados podem estar refletindo muitas vezes o significado da energia como uma demanda cidadã. Isto pode se repetir nos demais países e regiões da América do Sul. Para diferentes estados ou regiões periféricas brasileiras ou da America do Sul, a expansão do consumo de energia nem sempre corresponde à expansão esperada do setor industrial (vide o caso do estado do Pará (TAVARES; COELHO; MACHADO, 2008).

O consumo de gás natural também aumentou na última década no Brasil. Em 1998, o Brasil consumia menos de $8 \mathrm{Gm}^{3}$ de gás natural, quase triplicando o consumo em 2007, para 23,7 $\mathrm{Gm}^{3}$. Mesmo assim, o consumo nacional ainda permenece inferior ao da Aregentina e Venezuela.

A crise econômica internacional também provocou uma queda do consumo energético no setor industrial de $8 \%$. 
Estes dois países são os principais produtores de gás da América do Sul, todavia, grande parte das reservas está em solo venezuelano. Outro país com significativa reserva de gás é a Bolívia, que se tornou o principal exportador do continente, com uma exportação de $11 \mathrm{Gm}^{3}$, sendo o Brasil o principal consumidor por meio do gasoduto Bolívia-Brasil. Segundo dados do MME, do total consumido de gás natural no Brasil, apenas $4 \mathrm{Gm}^{3}$ são destinados a setor energético; a maior parte do gás natural $\left(9,2 \mathrm{Gm}^{3}\right)$ supre as necessidades do setor industrial, em particular da indústria química e metalúrgica (ANEEL, 2008).

Segundo a EPE, o segmento residencial cresceu por meio de uma contínua expansão do número de residências consumidoras, que chegou a 56,5 milhões de unidades em março de 2010 . O consumo industrial registrou crescimento de $12 \%$ entre março de 2010 e igual mês de 2009, para 15 mil GWh. "É a primeira vez, desde novembro de 2008, que o consumo das indústrias atinge este patamar, em uma evidência de recuperação da atividade setorial como um todo", informou a autarquia. A recuperação do consumo industrial se observa, principalmente, nas atividades de siderurgia e extração mineral, cujas indústrias foram as mais afetadas pela crise econômica. "Isso parece explicar o aumento do consumo na Região Norte (+11,6\%), que, segundo analistas, é condicionado pelo comportamento das indústrias no Pará (que representa $80 \%$ do consumo regional), em Minas Gerais $(+26 \%)$ e no Espírito Santo $(+60 \%)$ ", destacou a EPE (Economia/Notícias, 26/04/2010). Tudo isto é, no entanto, no mínimo, discutível.

Pode-se concluir que, para o caso dos estados centrais ou mais desenvolvidos, os projetos de geração de energia elétrica estão ainda mais voltados para o consumo industrial, do que os estados periféricos, isto é, para produção de semimanufaturados e manufaturados para exportação, do que para o crescente abastecimento residencial. O consumo de energia também permanece desigualmente distribuído pelo território nacional. ${ }^{12} \mathrm{~A}$ indústria continua sendo o principal consumidor de energia no Brasil, porém, há um aumento crescente do consumo residencial urbano e um aumento cada vez maior do consumo comercial.

${ }_{12}$ Mais da metade do consumo de energia permanece na região Sudeste e Centro-Oeste, onde se concentram a maior parte dos consumidores industriais e residências, $62 \%$ dos 435,6 mil Gwh consumidos em 2007 em todo país (ANEEL, 2008). A região Norte do país por um lado era o menor consumidor de energia em 2007, representando apenas $7 \%$ do consumo nacional; por outro lado é a região que nos últimos dez anos mais cresceu em consumo (54\%), enquanto o SE/CO expandiu o consumo em apenas 19\% - as regiões Sul e Nordeste cresceram $32 \%$ e $24 \%$, respectivamente, entre 2000 e 2010 - Dados do Operador Nacional de Sistema Elétrico (ONS).
O crescimento visado pelo modelo econômico do país, que inclui atividades eletrointensivas como a produção de alumínio, de aço e de cimento, entre outras commodities, dependerá das evoluções das conjunturas nacionais e internacionais. Assim, a dinâmica da industrialização, de acordo com o atual padrão de desenvolvimento, diz mais respeito à atual inserção brasileira no mercado internacional ou a globalização - a qual a produção ampliada de energia encontrase ajustada - do que por algum ditame de alguma restrição energética.

\subsection{Formação de redes nacionais e internacionais de transporte e de energia}

As fontes de gás natural, as quedas d'águas e os estímulos à formação de redes são estratégias ao desenvolvimento econômico e social dos países e da região Sul-Americana. As redes de energia hidrelétricas não são incompatíveis com as redes de infraestrutruras energéticas de origens diversas na América do Sul, pelo contrário, as redes de gás natural geram potenciais para energias termoelétricas e de interconexões internacionais sul-americanas, complementado as redes de energia que integrarão países da América do Sul.

As carências em infraestrutura de energia (e nos setores de transporte, telecomunicações, logística e saneamento) parecem ser os maiores gargalos a serem enfrentados para o desenvolvimento da América do Sul. Os esforços para ampliar a rede de energia, rodoviária, a malha ferroviária, hidroviária e telecomunicações são crescentes.

O Mercosul, criado em 1991, tem contribuído para ampliar a infraestrutura física dos países do Cone Sul, nos anos de 2003 e 2004, a ele agregaram como membros associados o Chile, a Bolívia e a Venezuela. O Pacto Andino (1996) foi relançado e se tornou, em 1996, a Comunidade Andina de Nações (CAN). Por sua vez, desde 2000, a Iniciativa de Integração da Infraestrutura Regional Sul-Americana (IIRSA) visa desenvolver a integração física: infraestruturas de transporte, energia e telecomunicação da América do Sul, em dez anos. Além de tentar construir uma identidade comum e uma cidadania sul-americana, esta integração está voltada para em particular: a) apoiar a integração de mercados; b) apoiar a consolidação de cadeias produtivas; e c) reduzir o custo sul-americano.

Em 2004, foi criada a Comunidade Sul-Americana de Nações. Dela fazem parte 12 Nações, incluindo a Guiana e o Suriname e todos países da América do 
Sul, com exceção do Chile e Equador. A Comunidade se tornou a União de Nações Sul-Americanas (UNASUL) em maio de 2008.

A integração das bacias - Bacia Amazônica e do Orenoco, ao norte, e da Bacia do Prata, ao sul do país, é vista como estratégica. Estas bacias adquirem ainda importantes papéis na formação de corredores de exportações e importações que deverão integrar países da América do Sul. Redes energéticas, bem como de transporte de intercomunicações, logísticas podem orientar e estimular fluxos de commodities entre países, dinamizando fronteiras que podem ser fronteiras econômicas, além de já serem "fronteiras políticas". As visões de vigilância e desenvolvimento mudaram. Há, portanto, uma visão militar das fronteiras políticas que precisam e tendem a ser substituídas por uma visão econômica estratégica.

A formação ou a expansão dos corredores de commodities, entretanto, dependem de logísticas, de redes de transporte e de energia (hidroelétrica ou termoelétrica movidas a gás), sobre a qual refletimos. Nossa indagação diz respeito aos indícios de que uma rede hidrelétrica pode estar sendo construída em complemento a rede do gás (gás oriundo do Urucu-AM - Brasil, gás da Bolívia, Argentina, Venezuela, Colômbia etc.). As fronteiras do Brasil e dos países fronteiriços da América do Sul são ricos nos dois recursos.

Ao sul do Brasil, a rede hidrelétrica do país, marcada por grandes matrizes geradoras, teve início com Itaipu (um projeto binacional). Ao norte, a hidrelétrica de Tucuruí deu partida à formação de uma rede cuja continuidade inclui as hidrelétricas aprovadas no rio Madeira, Jirau e Santo Antônio, e a usina de Belo Monte, no Xingu. A região sul do Pará conta com o linhão de Tucurui que segue caminho do Nordeste, mas, particularmente, do Maranhão. A linha de transmissão Tucuruí-Manaus está em construção e segundo previsões ficará pronta em 2012, antes da conclusão de Belo Monte, em 2015. As duas grandes empresas estatais brasileiras, Petrobras e Eletrobras e a CVRD (Vale), uma multinacional com sede no Brasil, ampliam seus investimentos na América do Sul, assim como as maiores construtoras. A Eletrobras constrói hidrelétricas, enquanto a Petrobras investe no gás, não obstante seus conflitos recentes na Bolívia. A CVRD (Vale) faz funcionar a mineração do cobre e de ferro na Amazônia e em países andinos.

A energia de Belo Monte deverá, segundo planos do governo federal e da Eletrobras fazer, portanto, parte de um sistema integrado de transmissão de energia que se estenderá para a Amazônia Ocidental (Pan-Amazônia), unido às linhas de transmissões das usinas hidrelétricas de Santo Antônio e Jirau no rio Madeira.
Os gasodutos (Figura 1) Urucu-Porto Velho e Coari-Manaus deverão dotar a região amazônica de uma rede de distribuição de gás para as principais cidades da região Norte do Brasil, integrando estas às cidades de Imperatriz e São Luís, no Maranhão, devendo ser ampliado até Fortaleza, conectando, dessa maneira, duas regiões brasileiras por meio dos gasodutos de transporte.

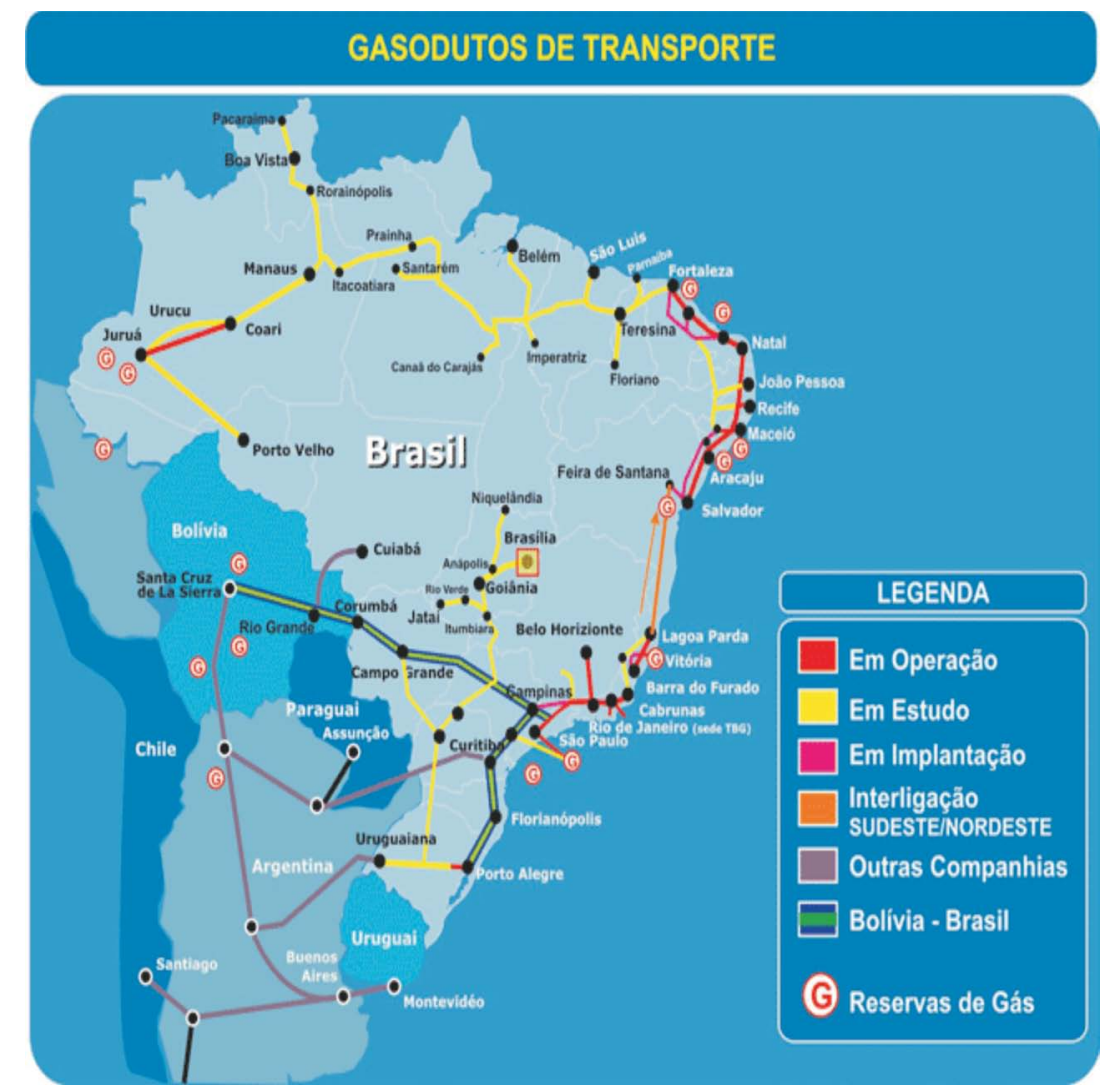

Figura 1. Mapa de Gasodutos de Transporte.

Fonte: www. http://www.abegas.org.br/info_mapagasoduto.php. Acesso em 14/11/2010 - ABEGAS - Associação Brasileira de Empresas Distribuidoras de Gás Natural.

Além da integração por meio de gasoduto, a Amazônia deverá ser conectada por meio da rede de produção e distribuição de energia a ser produzida pelas três hidrelétricas já referidas: Belo Monte, Jirau e Santo Antônio, criando eixos de integração inter-regional e internacional. A associação das redes de gasodutos com as redes de distribuição de energia produzida por hidrelétricas e termoelétricas proporcionará o fortalecimento de laços comerciais entre Brasil, Argentina, Bolívia e futuramente entre Venezuela e Peru (PIQUET; MIRANDA, 2009). 
A possibilidade de execução de redes infraestruturais de energia, de hidrelétricas ou de gasodutos, e os avanços possíveis dos corredores de exportação de commodities estão certamente ligados à manutenção dos preços favoráveis das matérias-primas e das commodities, minerais e alimentares, no mercado global que continuarão a motivar os interesses de novos (CSN, GERDAU, e outras empresas a serem incentivadas) e relativamente velhos (CVRD e Alcoa) consumidores na região amazônica. Assim, a motivação dos atores empresariais diz mais ao futuro do que a situação atual.

\section{CRÍTICAS E INCERTEZAS DO “MODELO ECONÔMICO”}

No caso do Brasil e de seus vizinhos, os envolvimentos e empenhos dos Estados no processo de atrair investidores foram nítidos, criando ou recriando novas fronteiras econômicas da Amazônia (Oriental e Ocidental). Além da conclusão das eclusas de Tucuruí, asfaltamento das BR-163 (Cuiabá - Santarém), da rodovia Transamazônica e das construções de usinas hidrelétricas nos rios Madeiras e Xingu. O objetivo principal será a formação de redes infraestruturais e o estimulo à integração ou interconexões entre países da América do Sul.

Trata-se de projetos desenvolvimentistas estimulados por estados também desenvolvimentistas e movidos por ambiciosos planos para a América do Sul. A prova disto, no caso brasileiro, é que o BNDES financiará $80 \%$ da obra de Belo Monte. Além de juros subsidiados, o BNDES dilatou o prazo inicial de pagamento para 30 anos. O Estado brasileiro, todavia, não dispõe deste capital, devendo emitir títulos da dívida pública. Haverá também isenções fiscais. Em outras palavras, a sociedade caberá subsidiar a energia a ser consumida pelos grupos privadas. Um típico projeto desenvolvimentista?

As ênfases nas exportações de matérias-primas in natura ou semiprocessadas ou nas commodities e nos corredores de exportação parecem não ter sido mudado substancialmente desde que o mercado chinês se revelou próspero. O BID e os fundos americanos, como o Global Infrastruture Partners, ou nacionais como a PREVI, os fundos chineses estariam interessados a investir em infraestrutura no Brasil ou na América do Sul.

Noções como "fronteiras de commodities", "verticalizações" ou "cadeias produtivas", "corredores de exportação" e "redes" passaram a ter significados importantes na versão atual do modelo econômico brasileiro. O que há de novo neste modelo parece ser o modo de produzir (ainda mais intensivo em tecnologia), o volume elevado de produção, de transporte (mais investimentos logísticos) e maior responsabilidade ambiental - ainda que no nível além do desejado e sem excluir conflitos entre privado e coletivo (DOMINGOS, 2007, p. 165). Certamente mudou também o fato de o projeto ser agora conduzido por um governo do Partido dos Trabalhadores - PT, que assume e exerce o controle estatal sobre o consórcio.

Os caminhos da economia têm sido incertos, dado o custo crescente de energia, pela duração incerta da crise financeira dos países industrializados e endividamento das empresas. As tendências identificáveis se alteram rapidamente. As mudanças no ramo do alumínio nos surpreenderam e podem ser um indicador não só do endividamento ou da opção da empresa, a Vale, em sua aposta ou especialização na exportação do ferro e seus derivados no ferro como indicadores dos efeitos das elevações no preço da energia e baixa no preço internacional do alumínio. Roger Agneli ${ }^{13}$ sobre a venda de ativos de bauxita, alumina e alumínio a Norsk Hydro:

A indústria de alumínio tem passado por uma forte reestruturação nos últimos anos e, hoje, os grandes produtores no mundo são integrados. Fizemos um novo grande player na indústria do alumínio. Integralizamos os ativos de bauxita e alumínio na Nork Hydro, que tem acesso a energia barata tanto na Noruega quanto na Arábia Saudita. Se a Hydro crescer em alumínio, cresceremos junto. Os investimentos no Brasil estão preservados.

Tal declaração é demonstrativa de que as mudanças são reais, mas as direções por elas assumidas podem ser ainda incertas. As empresas nos países ou regiões da América do Sul terão assim que encontrar seus caminhos a partir do quadro global também incerto. Não podemos esquecer que o processo de "modernização" é quase sempre resultado da combinação ou interação de fatores externos e internos, em grande parte, imprevisíveis.

\section{CONCLUSÕES}

As disputas, as polêmicas e as dúvidas sobre as hidrelétricas continuam, apesar de estes empreendimentos continuarem a ser centrais para a composição da

13 Presidente da CVRD, 2001. Entrevista a Chiara Quintão, Jornal O Estado de São Paulo, Caderno Economia, de 22/05/2010. 
matriz energética brasileira e sul-americana e para a expansão em rede integrada de energia elétrica e de gás. O gás, causador de danos sociais e ecológicos mais sérios, além de ser uma alternativa mais cara que a água, parece ser um complemento de uma rede energética a ser construída, integrada e consolidada na região. Assim, o mesmo processo conflituoso em que são modificados os ecossistemas e são afetados os usos tradicionais do solo, é construído uma integração econômica interamericana.

A expansão energética em rede integrada (em construção) também tem se apresentado ligada a uma lógica mercantil de exportações de commodities, motivadas pelas crescentes importações da China. Esta racionalidade baseada nos estímulos aos eixos de exportação que envolve outros investimentos logísticos, como transportes, também tem demonstrado grandes potenciais de integração regional. Cabe questionar então, se o padrão de desenvolvimento a ser construído com a contribuição das políticas energéticas reforça a soberania de todos os países envolvidos? Se não, que outras alternativas de integração regional podem ser construídas?

Se aos poucos o processo de estabelecimento de um novo padrão de desenvolvimento vai se tornando cada vez mais claro, o mesmo não se pode dizer de seus ganhos sociais. A importância da energia como fonte de cidadania para famílias de diferentes estratos sociais, ainda tem muito a sua presença restringida à retórica. Igualmente restringido está a inserção das lógicas de atores não hegemônicos, particularmente a demandas efetivas dos moradores locais/ regionais. Haverá espaço para estas demandas ou serão sacrificados em prol do tipo específico de desenvolvimento? Longe de serem respondidas, essas perguntas apenas procuram demonstrar a importância crescente das questões de soberania, autonomia, cidadania e sustentabilidade no debate de produção energética.

\section{REFERÊNCIAS}

ANEEL. Atlas da Energia Elétrica no Brasil. Brasília: Agência Nacional de Energia Elétrica. 2008

DOMINGES, J. M. Aproximações à América Latina. Rio de Janeiro, Civilização Brasileira, 2007.

EGLER, A. C. As Américas: singularidades de um continente plural. In: OLIVEIRA, M. P. DE; COELHO, M. C. N.; CORRÊA, A. M. (Orgs.). O Brasil, a América Latina e o Mundo: Espacialidades Contemporâneas I. Rio de Janeiro: Anpege; Lamparina, 2008. p. 142-167.

BRASIL. Ministério de Minas e Energia. Eletrobras. Relatório de Impacto Ambiental - RIMA. Aproveitamento Hidrelétrico Belo Monte. Brasília: MME/ Eletrobras/Andrade Gutierrez/Camargo Corrêa/ODEBRECHT, 2009

BRASIL. Ministério de Minas e Energia. Eletrobras. Plano Nacional de Energia. Brasília: MME/Eletrobrás, 2003.

PIQUET, R.; MIRANDA, E.; DAMIANI, R. Petróleo e Gás: das tensões geopolíticas latino-americanas às mudanças sócio-espaciais no Brasil. In: X SEMINARIO DA RED DE INVESTIGADORES SOBRE GLOBALIZACIÓN Y TERRITORIO, 10. 2008, Santiago de Querétaro. Anais... Santiago de Queretaro: Universidade Autónoma de Querétaro, 2008. v. 1. p. 1-20. 2008

.; MIRANDA, E. Indústria de Gás no Brasil: implicações territoriais, incertezas e perspectivas. Revista Universitária de Geografia, Bahia Blanca, v. 18, p. 163-183, 2009.

PAIM, E. S. II RSA, É esta a integração que nós queremos? Amigos da Terra. Disponível em: http://www.natbrasil.org.br/Docs/instituicoes_financeiras/ iirsa $\% 202003$.pdf.

SEVÁ FILHO, O. (Org.). Tenotã- Mõ. Alertas sobre as Consequências dos projetos hidrelétricos no rio Xingu. Belém: São Paulo: IRN/Comissão Pró-Índio de São Paulo/Instituto Socioambiental/FASE, 2005.

SILVA, E. B. de. Infrastructure for sustainable Development and Integration of South América. A report to Business Concil for sustainable Development. [s.1]: Corporación Andina de Fomento; Compania Vale do Rio Doce; Bank of America; Companhia Auxiliar de Empresas de Mineração, 1996. 
TAVARES, M. G.; COELHO, M. C. N, e MACHADO, L. O. Redes de Distribuição de Energia e Desenvolvimento Regional. In: COELHO, M. C.; MONTEIRO, M. A. M. (Orgs.). Mineração e Reestruturação Espacial da Amazônia. Belém: NAEA/ UFPA, 2008. p. 141- 184.

\section{Periódicos:}

Economia/Notícias, 26 abr.2010.

Folha de São Paulo, Caderno Mercado, p. B1, 25 maio 2010.

Folha de São Paulo, Dinheiro, p. B4, 18 abr. 2010.

Globo News (1 de maio de 2010). Entrevistas como o Dr. Maurício Tolmasquim e Dr. Carlo B. Vainer.

O Estado de São Paulo, B6, Caderno Economia, de 22 maio 2010.

O Estado de São Paulo, B2, Economia, 24 abr. 2010.

O Estado de São Paulo, B4, Economia, 24 abr. 2010.

Revista Carta Capital, 28 abr. 2010.

Revista Exame, v. 44, n. 7, abr. 2010.

Web http://www.abegas.org.br/info_mapagasoduto.php. Acesso em: 14 nov. 2010.

Texto submetido à Revista em 22.9.2010

Aceito para publicação em 19.12.2010 